\title{
ENCHANTED OBJECT: INDIAN SARI, NEGOTIATING THE ONLINE AND THE OFFLINE SPACE
}

\author{
Seema Khanwalkar \\ CEPT University, India \\ seema.khanwalkar@gmail.com
}

\begin{abstract}
This paper is an attempt to understand the intersections between the internet, global cultures and technology, and the material object, the Indian sari. The Indian Sari, like other ethnic clothing, has always acted as a means of affirming position and agency for Indian women. Even today it is a significant part of the communicative grammar for its offline avatar. But its online presence makes this garment even more discursive. Typically online communities, in linguistic terms, are 'cultural communities' (paradigmatic) where knowledge is shared to deepen expertise, and offline communities are 'communities of practice' (s yntagmatic) where people share concerns, passions, and problems to deepen interaction. But as Umberto Eco says, more and more paradigmatic communities are becoming syntagmatic, and the Indian Sari is in an interesting intersection of offline and online contexts as the wearer, the garment, and the transactions all create discursive spaces
\end{abstract}

Digital Age in Semiotics \& Communication, Vol. I, No. 1, Spring 2018, Pp. 121-140 
that implicate the global and local in identity formations. It also forces us to relocate the Sari as a signifier and reexamine its materiality in relation to its floating presence.

Keywords: Global cultures, technology, material object, online space, online communities

\section{Paradigm of Online Cultures}

The intersection of global cultures, technologies and markets has created new paradigms of consumption in the digital world. The Internet and other digital technologies comprise a complementary set of communication with a three-prone objective: inform, recall, \& persuade (Nyeck, 2004), characterized by an original interactivity since the user is interacting with the media and with the product through the media. Digital technologies have offered a new distribution network to companies, through so-called e-commerce. A very basic characteristic of the digital world is that it has neither physical nor technological boundaries (Okonkwo, 2009); this means access to a limitless space. And with the emergence of social media, consumers become empowered and gather themselves in eco communities, still without any geographical or cultural boundaries (P. R. Berthon, Pitt, Plangger, \& Shapiro, 2012) when successful digital strategies set longlasting relationships with consumers, via the creation of global and crosscultural brand communities, with easier, more accurate identification of their desires and needs (Chen, 2001)

Most online communities are created between people who have something in common. They usually do not know each other, but are aware of being part of the community. As Anthony Cohen (1985) would describe it, such communities are 'entities of meaning', founded on a shared conglomeration of normative codes and values that provide community members with a sense of identity. The structuralist terminology of 'paradigmatic' and 'syntagmatic' applied here to the two types of community further clarifies the two as 'cultural communities' (paradigmatic) and 'communities of practice' (syntagmatic) ${ }^{1}$. Online communities are typically cultural communities, where members share expertise of some kind. In communities of practice, members share concerns, passions, and problems and deepen their knowledge by interacting on an ongoing basis. But a lot of paradigmatic communities are becoming syntagmatic communities as they

${ }^{1}$ The application of the two structuralist terms has been referred from Tardini, S and Cantoni, L. 2005 
become more and more interactive. Umberto Eco (1983) would call these interactive objects co-constructed by their publishers (writer, designers, engineers etc.) and their users. The former develop a sort of language with basic elements (nodes/lexias, or sub-node items) and link rules, while the latter choose which paths to activate.

\subsection{Digital as a Space}

Calling the digital a space and recognizing its communicative and social power has also led to investigations about the nature of manifesting and traversing this space by both individuals and social groups. Humanistic geographers have called 'Space' a wide open and continuous area of action that individuals understand by experiencing movement, while place, they say, is a discrete space devoted to the ideas of staying, resting, engagement aspects, that relate to 'value' and a sense of belonging' what Yi-Fu-Tuan called 'topophilia (Tuan 1974: 4).

What then is the nature of dwelling in the digital? The digital is a complex, fluid and pervasive space as Maggi ${ }^{2}$ conceptualizes and is not bodily based but has a strong cognitive connotation. To understand the nature of dwelling in this space, Maggi (2014: 90) turns to Bullnow's (1963) theory of Space that is anthropological and not physical or mathematical. Bullnow calls it the 'Hodological Space' a space of movement. The familiar, the units that are part of our cultural knowledge, are 'Safe' in a hodological sense, Maggi says. The act of moving through space is therefore a continuous act of reinterpreting as safe or as hostile what surrounds us. Streets become networks, a safe way to move into the world. What lies beyond the street is experienced from the 'safe street'. The digital experience, according to Maggi, is compared to the motorists' experience on the safe street. Hence exploration of the digital moves first along the safe trails already set by others, trails that become conventional over time. These conventional schemes are semiotically part of a larger cultural organism. 'We learn to move within the digital by observing the behaviors of the social groups we get in touch with, and by following their movement schemes they are used to.' (Maggi 2014: 90)

The digital world is seen as an ecosystem that includes, for example, the websites and apps that manifest the digital place, not any single one of them, nor their sum. It also includes the human interaction and the narration that spans all these channels. This first person experience is identification with the digital self and makes us actants ${ }^{3}$ of a story articulated through

\footnotetext{
${ }^{2}$ Maggi in Resmini, A (ed), (2014, P.90), Reframing Information Architecture

${ }^{3}$ The concept of 'actants' is inspired by Vladimir Propp's (the Russian Formalist) and sub-
} 
the digital channels. This narrative attribute of the digital space means that the space is a textual manifestation of narrations. It confers us with roles and the grammar for those practices of interaction we will be a part of. The forces of the digital space have consequences for the way people move and interact within them. This is an algorithmically controlled environment encouraging people to perform actions in a pre-coded system. Umberto Eco (1979) proposed a theory of textual cooperation that, when applied to a digital space, helps to understand the movement within a digital space as purely interpretative rather than a bodily movement. Umberto Eco says the textual strategy implicit in the digital space requires a model reader who must fulfill the requirements to actualize the text's potential content; the reader interprets the content on the basis of what it allows the reader to do. So, how then do spaces such as Facebook and Twitter construct the identity of their users and their social interactions?

Maggi proposes three formal traits that Facebook and Twitter have in common:

They both allow individuals to go beyond their 'real' social networks of family, friends, relatives, and colleagues, and to touch unreachable groups.

Built into both are two dimensions to express their identities. The Synchronic dimension that constitutes a fixed identity of the self which forms the core information-a name, a short bio, a picture etc., and the diachronic dimension that includes all the content posted over time and eventually becomes a log of the person's evolution on the site.

The identities constructed by these two dimensions happen in three ways according to Maggi: a) 'Self telling', or ways and mechanisms for telling one's story for personal and public benefit; b) 'Pervasiveness', or ways and means to link one's real identity to the one represented in the digital world; and c) 'Intersubjectivity', or ways and means to represent and expose the relationships between individual and others.

The task of representing the self on Facebook, Maggi says, essentially relates to the 'exhibitionist narrative program', or the posting of biographic information, content, and performing actions such as shares or likes. Our identities are clearly linked to stereotypical knowledge that Facebook

sequently A.J.Greimas's theory of 'actants'. Propp began by linking spheres of actions to characters offering an important insight into the dramatic text and to look for patterns in folklore - also referred to the 'deep structure'. Greimas went further to assign 'roles' to characters and once a character assumes a role; he becomes an 'actant'. For further reading, see Propp's 'Morphology of the Folktale' (1928) and Greimas, 'Structural Semantics' (1966). The concept of 'actants' here essentially aims to highlight the digital text and the interactions within its coded system. The reader in this case is guided by the codes and accomplishes his/her role as an actant through participation and interpretation. 
already possesses - so we identify with traits such as movies we like, places we visit, etc. We declare some indicators about ourselves, and comply with some pre-existing elements that we are forced to choose, like the relationship indicator. So in narrative terms, finding an adequate element in the Facebook list ensures that we attain a sanction, and if we do not, then we find ourselves in violation of the 'normality' of Facebook.

'To be on Facebook means to flatten our personality to the stereotypical person template available on the platform: whoever is not willing to do this will not fully get in tune with the place and its genus loci' (Maggi 2014: 91)

Maggi confirms this when he says that at the discursive level the synchronic profile information is shown through a static layout predesigned for us.

\subsection{Objects on the Internet}

Digital spaces have most certainly compelled us to think about a 'narrative of objects'. Alexis Lloyd (2013 puts it succinctly in this post:

As more of our objects and environments become actuated, connected, and data-enabled, these enchanted objects are developing the capacity to contain their own stories. An object can remember its history, can understand how it is used, can talk to other objects around it to understand its environment. As these capabilities evolve, objects no longer become inert backdrops to our experiences, but active participants in our world that can share stories about themselves and us.

Alexis goes on to elaborate on the narrative potential in this framework that is borrowed from David Rose's (2011) term 'enchanted objects':

'The first is the construct of objects as portals -- objects that can be used as totems or touchstones to draw you into a story, to transport you to another time or place through the locus of that object. We currently infer the history of our things in broad and abstract ways, through the quality of scratches and wear, through the patina of age, through markers and labels and signs of personal possession. But what if that history became more literally inscribed, either recorded by the object itself or written to the object by an author?'

Does the internet as a space privilege the object to the extent that the Indian Sari thrives as many other objects, ridiculous, mundane (like a toaster) and profound, become the frontiers of web-based technologies? 
Is it a case of overreach or a demonstration of the fact that the internet of things' is the next big thing in human lives? As Doug Thomson (2013) says,

And much like Facebook has become, for many, a kind of ambient social backdrop in their life, the happiness of your toaster or the temperature of your living room will be a kind of mesh that underpins our feeds and pokes, a humming kind of ambient noise that auto tunes itself based on mood or location.

What does it mean for those narratives to exist? Who gets to author those stories? Who wants to listen to them and in what contexts? Do objects become storytellers themselves or do they require human authorship and interpretation? What do these questions foretell for the Indian Sari, both offline and online? That the Sari as a mode of negotiating physical and cultural inter-subjective spaces and relationships is indeed a compelling argument. But with the sari shifting its inhabitation between the physical and the digital, it is even more compelling to see the impact of the digital as a space on women as actants in the digital narratives that surround the sari. Does the sari retain any of its material power, or does it get embroiled and tangled in the identity of the digital self? What do we experience of the sari in its online avatar?

\section{Anthropology of the Sari in the offline world}

The manner in which it is draped, parts of it used to express identities, cultural rules, and emotions, has made the Sari a significant aspect of being Indian. The cut fabric or the sari is the symbol of totality and integrity; it symbolizes the whole of manifestation. But the sari begs an anthropological understanding particularly because it is a 'living costume': it is witness to several costume changes and influences, and yet is carried forward by millions of women who have an intensely private relationship with the sari amidst changing times, changing aesthetics, and changing buying and selling formats. These are certainly big issues to contend with, and also a significant cultural juncture in India. There exists, however, a fundamental relationship with the sari that has acquired cultural overtones over a long period of time. The Sari takes the role of mediating the relationship between a person's sense of self and the outside world. Banerjee and Miller call it the 'fellow actor'4 whose presence must always be remembered.

${ }^{4}$ ibid 


\section{1 'Elevated Sari'}

But, 'the Sari forces a continued engagement, a conversation between the wearer and the garment. ${ }^{5}$ These conversations, so aptly described, include a 'subtle alternation between actions that become almost unconscious or automatic and others that are highly self-conscious'. The effect of the sari it has been well documented, and experienced, is to give a heightened sense of themselves, and that makes them believe that the sari makes the body more beautiful and womanly. In a detailed anthropological account of this relationship, Banerjee and Miller have given several accounts of the degree of intimacy between the two. They recount a very dominant metaphor of 'feeding the Sari', to prolong its life through proper starching, that is traditionally made from water used for boiling rice. A villager is quoted to have said that the sari has to be fed in order for it to have 'blood in its body', just like us human beings. And hence the life of the sari is comparable to the bodily needs and strength of the woman, who withers with age and wear and tear.

The Sari accommodates demands of rationality and modernity with ease as Banjerjee and Miller talk about the defense of the Sari by women, for its practicality for manual work, as well as its role in managing the complex contradictions in the world of Hindu religion. The pallu of the sari protects from the sun and from the male gaze, and the Sari as a cloth is in constant motion akin to the female body. The aspiration towards higher dignity, maturity and a sense of indian-ness is what makes the Sari 'elevated' according to this account. Wearers of the Sari aspire to reach this position that they feel can be achieved only through the Sari.

\subsection{Grammar of the Sari: Syntagmatic relationship of the parts with the whole}

The Sari is characterized by the display of the three main parts - the borders, the space-in-between that constitutes the length of the sari, and the end-portion, or the Pallu. For centuries, the aesthetics of the Sari has been expressed in these three spaces and the Pallu has always been the final reckoning that Indian women use in a variety of ways as a means of connecting with the world around them ${ }^{6}$. The Sari has always been bought for the beauty of its Pallu, and weavers and artists across the country painstakingly labor on this part, giving the sari its distinct identity.

\footnotetext{
${ }^{5}$ Banerjee and Miller, 2004

${ }^{6}$ Chui, D, 2011
} 
The anthropological significance of the parts of the Sari have been well captured in research on Indian cinema (Dwyer and Patel 2002,) ${ }^{7}$. These works have shown how the personalities of the actresses have been articulated by the manner in which they either 'control' the sari, or let the sari become their shield from the outside world. The veiling and the unveiling of the Sari as a metaphor has been beautifully captured across cinema; notable among these is the Bengali film maker Aparna Sen who has shown transitions in a woman's life, from being a devoted wife, to taking a lover outside her marriage. In both cases, the way she drapes her Pallu (first veiled behind the Pallu, and later unveiling it to convey intimacy with another man), is the central signifier and demonstrates that there is no need for words to express herself ${ }^{8}$.The notion of power and control associated with the Sari are like subtexts; idioms of self-worth and self-confidence in their relationship to the body. Indian women feel empowered in the act of controlling and rearranging their Pallu. This is particularly interesting in a modern context, when women use Sari as a mode of power in professional spheres. The Sari becomes a very strong tool in the communicative grammar of the woman's persona. She can actually take time to think, reword, and mull over what she has to say, while adjusting her Pallu, that can prove to be distracting to the observer, thus serving as a respite and interjection in a situation that she might have lost control over otherwise. Men, on the other hand, do find the Sari's Pallu very distracting - whether it stays, adjusted, or is falling off the woman's shoulders, because eventually it gives away a lot about who the woman is - confident, strong, self-assured, or meek, under confident, or even sexually open and comfortable about her body. Unlike most Western clothing, the sari, and in particular the Pallu, constantly moves and corresponds to various situations a woman may find herself in (Miller 2004). To hold the end of the Pallu particularly tight signifies anger, and to use it as cover hides an embarrassed face, making it a valuable non-verbal form of communication. A woman may have to cover her head after marriage as a sign of modesty, but she can equally use this to her advantage so that those around her are completely unaware of the feelings that lie behind the veiling. However, the pallu can also unintentionally portray a woman in a certain way, especially in an erotic light through its accentuation of facial features such as the lips or eyes (Miller 2004). In this sense, the pallu is an ambiguous object which is only at times completely in the control of women. By veiling one's face, a woman is able to hide her

\footnotetext{
${ }^{7}$ The descriptions below have been extracted from Dwyer and Patel's work on the visual culture on Indian Cinema

8 ibid
} 
emotions, but she is equally able to make them apparent to all those around her without uttering a word.

Interestingly, the culture of wearing saris also creates 'syntagmatic communities' as they are a network of relationships, hierarchies and part of the grammar of getting it right. The interactions over the Sari that take place offline create social relations and could be seen as 'syntagmatic communities. The online interactions are paradigmatic in the sense that these communities share something 'similar', in terms of interest etc. But these online paradigmatic communities are turning syntagmatic over time, as interactions between the members are creating networks and combinations of different elements during the process.

\section{Sari in the Digital Space}

The digital version of the Indian sari opens up an array of narrative perspectives, and embeds its collaborators as actants of a story articulated through pervasive information architecture across different channels. The digital space is creating new cultures of fashioning the Indian Sari in everyday life. It is undoubtedly a whole new imagination that is creating a 'new wearer' of the Indian sari, but is at the same time interacting with and reproducing the old, traditional wearer.

Digital space is not cohesive or closed; as Deleuze and Guattari (1988) suggest, it is a 'Spatial Striature', suggesting pathways to cross it and escape from it, encouraging individuals to let themselves be seduced by the possibilities of these actions. Unlike analogue spaces, digital spaces constitute the possibility of being acted upon and thus imply a strong human presence. The digital space for the sari is a textual manifestation of a narration. Conversations, expressions and descriptions characterize the online narratives of the sari. The tactile experience of the sari is carried forward through the verbal power unleashed on the user. The discourse is powerful enough to lure even the unsure, the uninitiated into its hypnotic dialogues. The internet is a predominantly expressive space, and everyone who is there feels compelled to articulate and address an audience that is largely unknown and unexplored. This is a paradigm that digresses from the known, the obligatory, and the traditional expectations for a sari in everyday life. The subtle semantics of the traditional sari and the articulations that go with it are altered on the internet, creating communities of wearers who are constantly sharing and conversing with one another, prodding, encouraging, and talking design, colors, textures and shapes. The object draws them into stories; the sari transports women beyond their physical realm and their immediate relationships. Women evolve their 
personas through these online expressions. The digital space allows the women to narrate for themselves and for the public, and they gleefully play between their real identities and their digital selves. They become willing 'exhibitionists' as the digital space seduces them and exposes the narratives. Storytelling and Imagination of the Online Sari

The online presence of the sari is a 'photographed' ideal. When you see it out there, you can relate to it through the flash-light, settings: the idealized image. It takes a leap of the mind to imaginatively drape it around oneself. So the sari is a source of myths online, it is all about the power of our imaginations and our ability to project our self-images. For example below is the extent to which women can transcend the material discomfort in order to project an easy inhabitation of the sari:

"I grew up in a middleclass household where women had a catchphrase for what they wore at home. Mothers and aunts would call it 'ghawrey-pawra sari'. In an unhappy translation, it would mean the sari meant to be worn inside the house; in other words, a sari soft and comfortable enough to accompany a woman's housekeeping movements. This was in contradistinction to the stiffness of the sari worn outside, one that did not lend itself to easy movements. In a Byloom sari such as this one, I find that the distinction has evaporated: it is possible to live in this cotton sari. ${ }^{9}$

Another example of mythical imagination that can take it to heights of poetic essence is this woman who compares the sari to the myth of Scheherazade, and weaving the complexity of the colours and lines into a climax:

"This is my favorite shade of blue, which, for want of a name, I call 'condensed blue.' While I could spend an afternoon talking about my love for this color, the truth is that its beauty could only be revealed in a fabric and texture as beautiful as this one. It's one that does not leave you at visual pleasure alone. I chose this sari from a photograph I caught in a newspaper. All the news in the day's paper was forgotten. ${ }^{10}$

This is Scheherazade's sari, I tell my niece: a story is waiting to be told. The colors seem to be engaged in a random conversation. In school, our art teacher once gave us a lesson on colors - how they were different and related at the same time. In this sari I see

\footnotetext{
${ }^{9}$ Quoted from https://www.facebook.com/byloomonline/?fref=ts

${ }^{10}$ Ibid
} 
the colors broken into lines and then, like the circular disc in the Physics lab which, when turned rapidly, brought all the colors into the climax of white, this sari dissolves and remains indifferent to mixing at the same time. ${ }^{11}$ "

It is almost like a poetic license unleashed on the fabric of the whole six yards of unstitched material. The written word takes over what was once discussed between women orally, and the written word 'insists', further entrenching the mythical realm of the Sari into the life and hearts of the women. And that is the enormous success of the 'Online Sari'.

"My friends have a word for this sari: 'Nilambari'. However it is not only the blueness of the sky that I find in it. I find this sari mysterious: I've never felt - and perhaps looked - the same on the various occasions I've worn it. I grew up in Himalayan Bengal, and when I look at this photograph, taken by a young girl whose hamlet I'd gone to visit, I find it almost emerging, as it were, from our blue mountains. That is a reminder to me, again, of how organic the relation between what we wear and what we live is."

The whole tactile and sensorial appeal of traditional saribuying is replaced with struggles in one's mind about possibilities and hopes, and in the ways the mannequin or mannequin-like bodies that wear the sari entice the viewer. The shapes of these bodies can be enticing and distracting, making it an out of the body experience. But nobody complains, and ultimately the mannequin wins the attention. What is even more interesting is that women are becoming blasé and very confident about their bodies when they send their picture for posting to the designer on their sites. It is an interesting way to overcome the 'mannequin block' and show up for what you are, how you look and for one's own body. But the sub-text is clear, 'show and flaunt', don't get left behind.

\subsection{Narratives of Arbitrations: Online avatars}

Expressions in the online space are mediated through 'avatars' ${ }^{\prime 2}$. In the digital context an avatar could be the representative of an individual user within a virtual space. According to Meadows, avatars are created according to the interaction between space and user, and may represent different world perspectives much as people themselves do (Meadows 2008: 13).

'Avatars may come in different sizes and shapes; they could simply be profile images used in a social media platform or advanced animated

\footnotetext{
${ }^{11}$ From https://www.facebook.com/byloomonline/?fref=ts

${ }^{12}$ The term avatar is originated from a religious context of Hinduism, and the Sanskrit origin of the word defines the worldly apparitions of divine beings (Partridge, 2005, p.148).
} 
character models inside a video game. The avatar is a sub-medium of online communications and expressions.' (Sengun, S: 150)

In the context of the Sari, the women who buy and the women who arbitrate are avatars, constructing an image of themselves much beyond who they are. The internet makes the buyer vulnerable and exposed to eyes that see her, evaluate her, and create expectations of their self-image too. She is the center of a different kind of a 'gaze' that is materialistic and commercial, as well as objective and critical. The designer, who creates these saris and presents them online, is also at the center of the entire gaze and is the mediator who ensures a parity and acceptance which makes every woman feel good about her image.

The avatar can become a more intimate construct of self than the physical self itself. Lacan observes that "other is the one who sees me" (Lacan 1992: 19) and through this gaze one feels the desire which cannot be fully realized in the physical. However in the virtual the user has the ability to create infinite linguistic representation of his or her self and fulfill each desire by phasing into the avatar and matching the gaze'

The Sari's designer is deeply conscious of the gaze on her and must become the avatar of the arbitrator, who does not allow for any unfortunate exchange between her viewers and buyers and creates an ambience of 'win-win' for all. Both merge into their 'avatars' to match their 'self-gaze' and the 'gaze' of the others, in an interesting fusion of a spatial condition orchestrated in and through the digital space. Below is a reproduction of dialogue taken from Facebook, an exchange between the designer and her online friend.

Na Lalidi. This was specifically made for someone. Planning to do a similar one in olive (instead of orange) and brown instead of ivory $^{13} \ldots$

Here the designer panders to the gaze of the viewer and her own selfgaze -

Sohini- as I browse your Fb shop, I kept wondering who you are. Ur vision is so clear, Ur passion is so reflective, Ur creations $r$ sooo unique, $\mathrm{Ur}$ values $\mathrm{r}$ so deep, $\mathrm{Ur}$ communication is so simple $\mathrm{n} \mathrm{Ur}$ connectivity to one $\mathrm{n}$ all around you is so straight! I had to write this note to you n say 'you r Blessed' indeed by ur Lord Ganesha”..... and with these lovely words Shiva Bhowmick becomes a part of

${ }^{13}$ Quote from https://www.facebook.com/DorDesignsBySohini/?fref=ts 
the DOR family.....Thanks so very much for the sweet message...u surely made my day..:) $)^{14}$

The Gaze also involves co-opting of family and friends..and thus grows and perpetuates online....

Kshamani-we are so happy that you and your ma are now parts of our family :) love the fact that she wore her saris for her birthday, which means a lot to us. Huge hug to ma and you : $)^{15}$

This in itself is a big boost to the women, who are essentially competitive and aspirational. The effect of images of other women who might look better and more attractive in these saris is mitigated by the designer ensuring the women that everyone looks lovely. Women have also expressed that they overcome their inhibitions after the initial mental blocks and go all out to flaunt their new saris and their new selves. It is a space for experimentation of not just new fabrics and textures, but also for who they are, and what they can look in new designs and new aesthetics.

Udd is a happy textile brand, we at Udd encourage the Bohemian Spirit and get inspired by folk -tribal art, which is then transformed into beautiful art fabrics!! We encourage artists at heart whether they be from rural India or young urbans!! ${ }^{16}$

We are designing a SPECIAL UDD Lengha set for an even More SPECIAL UDD woman- for the most important day of her life- we are thrilled- honored- excited- nervous!!

We worked on a special SHIV- PARVATI ON NANDI art work for her Lengha !! ${ }^{7}$

They get views and comments that make them feel elated and liked, and help them to take the next step, and get bolder in their experiments with the sari, making this space utopian and free from the constraints of a typical offline space.

\section{2 'Titled online Sari'}

Traditional Indian Saris have always been known by their titles which correspond to their weave, the region, or the style of design and printing - Kalamkari, Kanjeevaram, Paithani, Tangail, Bomkai, Madurai Cotton

\footnotetext{
${ }^{14}$ Ibid

${ }^{15} \mathrm{ibid}$

${ }^{16} \mathrm{ibid}$

${ }^{17}$ Quoted from https://www.facebook.com/Uddstories/?fref=ts
} 
etc. Designers on Facebook have created identities for their saris in continuation with this tradition, but in a metaphorical realm. 'Dor', UDD, Anga Chhaya, ByLoom, Nextiles, Raw Mango ${ }^{18}$....these are some of the titles that create individual identities for the designers and are umbrella terms that subsume the designer's intent. The metaphorical titles allow for unrestricted experimentation and expression for the designer, and allow her to borrow aesthetics from traditional prints, weaves, designs, textures and weaves. 'Inter-textual' and ambiguous title semantics fosters curiosity, and allows for a flexible attachment to the designs. Some designers like to maintain their personal name as the identity of their creativity; these belong to a different class who do not like to be in a competitive zone like most others. They create designs as their personal ideology, their belief in fabrics, traditional weaves, textures, colors and designs. They are in no hurry to arouse curiosity and their presence is deliberate, slow and easy. They make no announcements of their forthcoming creations, nor do they call out to their potential customers, they are happy being admired and liked for what they create by a few. Their designs are a carry forward of the original designs, and are presented as time-tested traditions, unlike the others, who create new forms and new aesthetics, experimenting and creating excitement around their forthcoming designs.

Black self-patterned supernet jacquard with rich embroidered border with contrast jamevar pleats in green $\mathrm{n}$ gold with matching blouse fabric... with elegant green gold latkans hanging from the pallu ends... ${ }^{19}$

\subsection{Digital Sari and democratic alliances}

The image of the object in the digital is the final image, without the experiences of the fabric, the wearing of it, the stitching of the blouse, the accessories, or any other live feeling that is mandatory with the purchase of the offline Sari. The conversation that surrounds the stitching of the blouse with the tailor is one of the most significant aspects of the traditional Sari culture. Some of this is attempted on Facebook, when the designer discusses this with her buyers and gives her options of how the final product will look. Some designers attempt to seal the transaction by offering to get the blouses stitched for the clientele, and identity is fostered by creating specific kinds of cuts and designs for the blouses.

The client on the other hand has a different relationship with the local tailor, with whom she shares a much more direct dialogue and even engages in almost a duel over the design, the delivery date, and the cut,

${ }^{18}$ Names of the online designer sari pages on Facebook

${ }^{19}$ Quoted from https://www.facebook.com/DorDesignsBySohini/?fref=ts 
and expresses her displeasure if something goes wrong. The tailor, in this case usually male, shares a familiar relationship with his client, given that as an outsider 'male' he is allowed to measure and comment on her changing body aesthetics, a sanction that he acquires over many years of transactions. The tailor can also be dragged into revelations of the new designs, or competitive aesthetics of other women, and co-opted into cultures of rivalry and envy. He tends to give them a sneak preview, a sneak peek at other's fabrics and designs and thus becomes a co-conspirator in their desire to look the best.

Online, this conspiracy angle gets all mixed up in articulations of 'democratic alliances' between the designer and the client. The designer has to ensure that none of her clients are betrayed, sometimes even fails to reveal any special designs made on 'customized' orders. It is a distance and a hard attempt to maintain parity between all her existing and potential clients. Her image is much more at stake, as her business depends on it. Like local vendors who claim rights over their territory, the local tailor, too is not looking actively for new clients. He exists in an oasis that he has created over years and years of personal interactions. The relationship he shares with each of his clients cannot be replicated online, because there are rules and codes of behavior that disallow any discussions beyond professional boundaries. Also, the terms of endearment online are very universal and applied to everyone equally. The terms of address usedare very similar, and though some of these designers do try (admirably) to include personal statements in their conversations about the designs, it is after all an 'open arena' that is being witnessed by others at the same time. The designer has to play a balancing act between making personal and endearing conversations with some and ensuring that she doesn't sound aloof and distant with others. Unlike the local tailor, she also has little access to the person's life, or real persona, so it is all in her imagination and her creation of this person that she addresses and can only hope that the person really is as 'wonderful' and 'amazing' as she imagines her to be.

Don't have any more of the fabric left. Besides this I am making another one with this same kalamkar ${ }^{20}$ in pleats on brownish mustard jute silk with real hand painted kalamkari work on the pallu...that will be ready soon. ${ }^{21}$

\footnotetext{
${ }^{20}$ Kalamkari or Qalamkari is a type of hand-painted or block-printed cotton textile, produced in parts of India and in Iran. The word is derived from the Persian words ghalam (pen) and kari (craftmanship), meaning drawing with a pen (Ghalamkar).

${ }^{21}$ https://www.facebook.com/DorDesignsBySohini/?fref=ts
} 
She does not have the luxury of being the relaxed, like the local tailor who knows that he has loyal neighborhood clientele for reasons beyond his competence and tends to get complacent in the knowledge.

Hello my lovely DOR peeps, a very bright $\mathrm{n}$ happy good morning to all of you. Just so you know, I will be away on vacation starting Thursday till the 22nd. During this time I will have limited access to the page, so if you have any queries, questions, concerns, do drop me a line and I will get back to you at the earliest...and once I am back in Mumbai, I will be back with yet another range of exclusive saris from DOR!!! So see y'all then...love n hugs... : $)^{22}$

See you all today evening. I will start Uploading around 7.30pm IST and will respond to all queries once the entire batch is uploaded. Please bear with me till then... :)) and all queries will be responded to on a first come first basis...there are 14 saris in the current batch... please do leave your email id as well. I am in the process of creating a DOR mailing list and plan to do catalogue from next batch for streamlining the entire process... :)) thanks once again and my apologies for not keeping my promise of uploading yesterday. See y'all then in a few hours...much love.... ${ }^{23}$

\section{4. 'Mirror Mirror': Self-Image in the online Sari}

An aligning theme is the 'dramatis personae' that women like to portray. Most women are seen smiling, very happy in their attire, posing for admiration, or are shown as 'communities of women', together in their aesthetics, walking the streets like cult queens to stake a claim on the space. So the women display personas like - 'articulate art aficionados', 'history buffs', 'art collectors,' 'conservationists', etc.:

Grids appeal to me in a way that is difficult to explain. Whether it is in the paintings of Paul Klee and Pete Mondrian, the alpana patterns around the tulsimawncho or the game of dots and crosses, there is something about them. To quote my niece again, this is an 'Arithmetic notebook' sari. What marks this sari out for me is the surprise that comes in the red border. ${ }^{24}$

I think one of the charms of a Byloom sari is that it is always quoting something or someone: a memory, a person, a period in

22 ibid

${ }^{23} \mathrm{ibid}$

${ }^{24}$ From https://www.facebook.com/byloomonline/?fref=ts 
history, even a mood. As someone who likes negotiating with the past in various ways (the tanpura in the background belonged to my mother-in-law, and when I framed it into a table, I thought it was one way of ensuring that she was in the living room whenever we had guests visiting), this is something about Byloom's aesthetic that appeals a lot to me. ${ }^{25}$

Just as the sari is the most beautiful 'anti-fit' garment we know, so is the Byloom sari's way of playing with it. Nowhere is this more apparent than in this sari which has a remarkable elasticity that lends itself to a wonderful drape. ${ }^{26}$

Truth be told, this is the most comfortable sari I've worn in my life. And in the villages where I visit on work, a female jute cultivator once asked me, 'Can you wear this sari to sleep? It looks so soft'. ${ }^{27}$

As with other Byloom saris, I can wear it in classrooms and under the sky. ${ }^{28}$

\section{Conclusion}

The traditional, offline sari can be folded, molded, non-starched, unironed, and unkempt, yet it still remains a 'sari'. Does this serve to achieve a sense of mastery or comfort with the sari? It is said to vindicate the sari's iconic status and the potential difficulties of inhabiting the garment. With 'elevation' comes the potential for a fall. The sari is not a 'rational' garment in the same sense as the other popular 'salwar kameez' ${ }^{29}$ has become over time in India ${ }^{30}$. The sari is far more flexible in its appearance and in its symbolism, and is far from the rational enterprise of modernity as Banerjee and Miller assert. It does not belong to the realm of science, efficiency, utility and output and is on the other side, where there is beauty, radiance and womanly glow. The two most popular garments in India straddle the platforms of the 'practical' and the 'symbolic'. In the midst of all this is the online sari that serves to create a dialogue of expectations, dreams,

\footnotetext{
${ }^{25}$ https://www.facebook.com/byloomonline/?fref=ts

${ }^{26} \mathrm{ibid}$

27 ibid

$28 \mathrm{ibid}$

${ }^{29}$ Salwar Kameez is popular attire originating in the north of India and Pakistan. The shalwar are loose Pajama -like trousers. The legs are wide at the top, and narrow at the ankle. The kameez is a long shirt or tunic, often seen with a Western-style collar; however, for female apparel, the term is now loosely applied to collarless or mandarin styled collars.

${ }^{30}$ See Banerjee and Miller, 2004 for further discussion on the Salwar Kameez and the sari
} 
aspirations and linkages. It has become a dialogue on the art of imagining, dreaming, wondering, and posing questions about the sari. In a strange way it seeks to remove the 'symbolic' from the essential sari and borrow imagery from the 'practical', in an attempt to make the sari more conversational. This online discourse seems to create the first few steps that the uninitiated, the curious, and the excited onlooker require to inhabit the sari in future. In a quirky manner it has replaced the maternal voices that surround the sari in Indian homes and is bringing in a soft, cajoling, convincing approval for all those women who dare to try it on. The online sari can be termed as a resounding success, its technological buffering notwithstanding, due to its 'narratives'.

The 'story' of the sari is being retold in multiple ways in the digital space, and it is this telling that is attracting the women to participate and 'retell' it further. But the essential sari remains where it is, steadfast, multifunctional, articulate in several spaces, and is still seen as the most coveted symbolic garment for a woman's beauty. It is the people around the sari who change, re-invent and celebrate the length and breadth of the same. The online space for the Sari plays a major role in reinventing the fundamental relationship of the object with the user. By making the Sari more accessible the online space breaks the constraints of physical space (be it of the house, the courtyard, the market or the tailor shop) and encourages an altered interaction with the object. The fluid typology of this online space, allowing users to connect different data sets to create instant representation, goes a long way toward de-mystifying the Sari and reinventing it as a cultural idea. 


\section{References}

Anderson, B. 1991. Imagined Communities: Reflections on the origin and spread of nationalism. Verso. London

Banerjee, M. and Daniel Miller, 2004. The Sari, Berg Publications

Berthon, P., Pitt, L., Parent, M., \&Berthon, J.-P. 2009. Aesthetics and Ephemerality: Observing and Preserving the Luxury Brand. California Management Review, 52, 45-66.

Bruzzi and Church-Gibson 2000, Fashion Cultures: Theories, Explorations and Analysis, Taylor and Francis, Routledge

Cassirer, E. 1944. An Essay on Man: An Introduction to A Philosophy of Human Culture. New Haven, CT: Yale University Press.

Chui, D, 2011, The Sari's pallu: An extension of the self in South Asia. Imponderabilia, The international student anthropology journal, Spring 10, issue 2

Cohen, A, 1985, The Symbolic construction of community, Routledge, New York

Dwyer, R and Patel, D, 2002. Cinema India: The Visual culture of Hindi films. Oxford

Duhaime, C.P., Joy, A. and Ross, C.A. 1995 'Learning to See: A Folk Phenomenology Of Consumption of Contemporary Art in a Canadian Museum, in J.F. Sherry, Jr.(Ed.) Contemporary Marketing and Consumer Behavior, pp. 351-8. Thousand Oaks, CA: Sage.

Eco, U. 1979. The Role of the Reader: Explorations in the Semiotics of Texts, Duke University Press

Eco, U. 1986. Travels in hyper reality. London: Picador.

Tardini, S and Cartini, L, 2005. A Semiotic approach to Online Communities: Belonging, Interest and Identity in Websites and online communities. IADIS International Conference e-society.

Tran-Van, M. 2013. Blog Business / Webmarketing / Management. In (Vol. 2013).

Larraufie, A.F.M, and KOURDOUGHLI, A 2014, The E-semiotics of Luxury, http://www.marketing-trends-congress.com/ 
Thomson, D. 2013. If This Toaster Could Talk: The Place of Stories on the Internet of Things. http://beekn.net/2013/10/if-this-toaster-could-talkthe-place-of-stories-on-the-internet-of-things/

Lacan, J. 1992. The Seminar of Jacques Lacan: Book VII - The Ethics of Psychoanalysis, 1959-1960. New York: W.W. Norton \& Company, Inc.

Lloyd, A. 2013. If This Toaster Could Talk. Narratives in the age of the smart object. http://www.theatlantic.com/technology/archive/2013/09/ifthis-toaster-could-talk/279276/

Meadows, M. S. 2008. I, avatar: The culture and consequences of having a second life. Berkeley, CA: New Riders.

Nyeck, S. 2004. Luxury brands online and offline: the case of French brands. European Retail Digest, 20-24.

Okonkwo, U. 2009. Sustaining the luxury brand on the Internet. Journal of Brand Management, 16, 302-310.

Reshmini, A. 2014. (Ed). Reframing Architecture. Springer.

Rose, D. 2011. Enchanted Objects, https://www.youtube.com/ watch?v=weTyZDNsOJo

Sercan şengün, a semiotic reading of digital avatars and their role of uncertainty reduction in digital communication, Journal of Media Critiques [JMC) P.150 http://www.mediacritiques.net

Tuan. Y. F. 1974. Topophilia: A Study of Environmental Perception, Attitudes and Values. Springer

Venkatesh, A and Meamber, L . 2006. Arts and aesthetics: Marketing and cultural production. Marketing Theory-MARK THEORY, vol. 6, no. 1, pp. 11-39, 2006

Websites: Facebook pages: Dor Designs by Sohini, AngaChhaya: an online boutique, Mahua Sarkar Sen, Raw Mango, UDD, ByLoom, Nextiles 